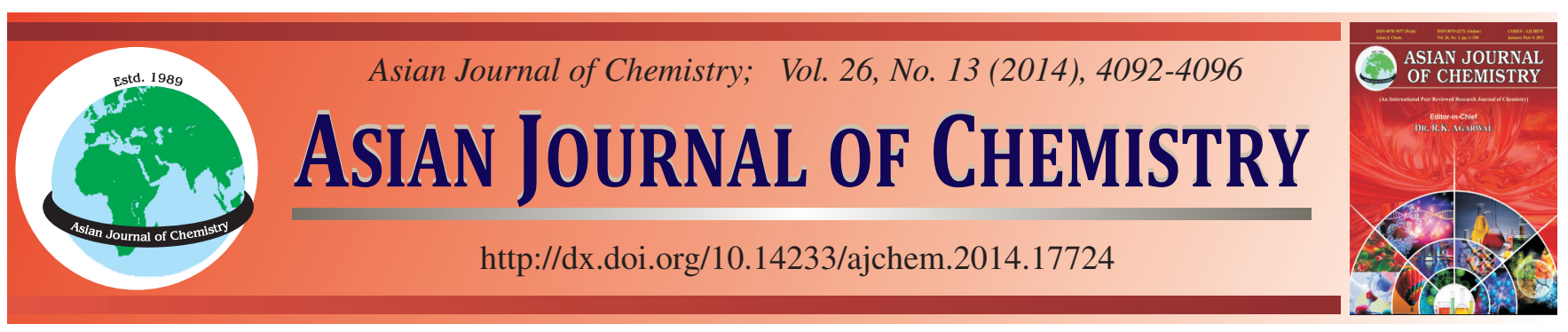

\title{
Investigation of Silyl-Amide Complexes as Catalysts for the Ring-Opening Polymerization of L-Lactide $\dagger$
}

\author{
Chanwoo LeE
}

Department of Innovative Industrial Technology, Hoseo University, Asan, Chungnam 336-851, Republic of Korea

Corresponding author: Tel: +82 41 5405892; E-mail: cwlee@ hoseo.edu

\begin{abstract}
A series of silyl-amide complexes $\left(=\mathrm{M}\left\{\mathrm{N}\left(\mathrm{SiMe}_{3}\right)_{2}\right\}_{2}\right)$ were examined as the catalysts for the ring-opening polymerization of $\mathrm{L}$-lactide. The poly(L-lactic acid) (PLLA) synthesized with the $\mathrm{Zn}$ complex showed a $\mathrm{M}_{\mathrm{n}}$ near the theoretical value with narrow dispersity. The $\mathrm{Zn}$ complex without 1-dodecanol added also gave a poly(L-lactic acid) with $\mathrm{M}_{\mathrm{n}}$ near 10,000 Da, although its molecular weight distribution was wide. The poly(L-lactic acid) obtained with the Sn complex in the absence of 1-dodecanol had a $\mathbf{M}_{n}$ higher than 40,000 Da, suggesting that the Sn catalyst involved in the insertion reaction with lactide should have higher activity for the polymerization. This steric space makes the coordination of L-lactide easier and causes faster rate of conversion in the early stage of the polymerization despite its small polarization.
\end{abstract}

Keywords: Silyl-amide complex, Dispersity, Molecular weight distribution, Polymerization, Catalyst.

ᄂ - - - - - - - - - - - - - - - - - - - - - - - - - - - -

\section{INTRODUCTION}

The present human society depends on fossil resources to support our comfortable life by consuming a huge quantity of energy and materials. However, massive use of fossil resources now causes harmful effects such as global warming, environmental contamination and shortage of fossil resources. Therefore, much effort is now paid to replace the conventional oil-based resources by renewable resources such as wind power, solar energy and biomass. Particularly the use of biomass is convinced to be effective for sustainable production and preservation of fossil resources, because it is derived from the atmospheric carbon dioxide via plant photosynthesis. In regard to materials, there has also been an increasing interest to develop new materials that are derived from renewable biomass-based resources such as corn, beet and other annually cropped products. These materials are called "bio-based materials". Use of these materials may also contribute to reduction of $\mathrm{CO}_{2}$ emission and excessive reliance on the fossil resources in human activities.

Among the biobased materials, the most promising is poly(L-lactic acid) (PLLA) that can be derived from lactic acid. The synthesis of PLLA can be done by direct polycondensation of L-lactic acid as well as by ring-opening polymerization (ROP) of L-lactide (L-LA), a cyclic dimer of L-lactic acid (Scheme-I). Although the former method needs severe conditions

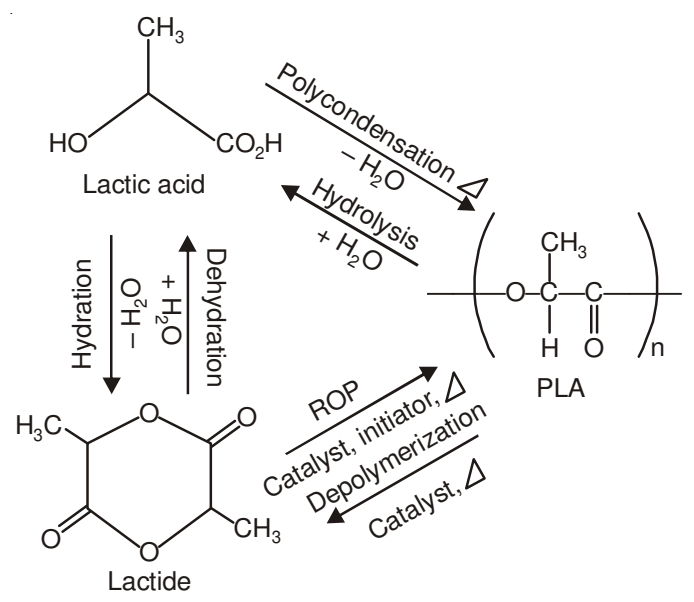

Scheme-I: Synthetic routes to PLLA: direct polycondensation of L-lactic acid and ring-opening polymerization of L-LA

to obtain a high-molecular-weight PLLA (high temperature of $180-200^{\circ} \mathrm{C}$, low pressure of at least $5 \mathrm{mmHg}$ and long reaction time), the latter method can afford a high-molecular-weight PLLA with narrow molecular weight distribution at relatively mild reaction conditions (low temperature of $130^{\circ} \mathrm{C}$ and short reaction time $)^{1-9}$. Consequently, ring-opening polymerization of L-lactide is adopted in the ordinary industrial production method of PLLA. 
Three reaction mechanisms have been proposed thus far for ring-opening polymerization of L-lactide: anionic, cationic and coordination-insertion mechanisms (Scheme-II) ${ }^{10}$. In the anionic polymerization, undesirable reaction such as racemization, back biting reaction and other side reactions are often caused by highly active anionic reactants to hinder the chain propagation. In the cationic polymerization racemization likely occurs because the nucleophilic monomer attacks the chiral center of the propagating chain. The loss of optical purity lowers the crystallinity of the obtained polymers. Other undesirable side reactions also decrease the molecular weight. On the contrary, the polymers obtained by the coordination-insertion mechanism can gain a large molecular weight and maintain high optical purity. Therefore, a variety of catalysts have been studied. Typically, metal alkoxides of different kinds of metals $\left(\mathrm{Sn}^{11-16}, \mathrm{Y}, \mathrm{Ln}, \mathrm{Fe}, \mathrm{Ti} / \mathrm{Zr}, \mathrm{Al}^{17,18}, \mathrm{Zn} / \mathrm{Mg}, \mathrm{Li}, \mathrm{Ca}^{19-24}\right.$, etc.) can be applied to ring-opening polymerization of $\mathrm{L}$-lactide. The standard catalyst system utilized for synthesizing high-molecularweight PLLA is tin(II) octoate with which lauryl alcohol (1dodecanol) is usually used as an initiator. This catalyst system has several advantages over the others in terms of solubility in organic solvents and molten lactide in bulk state, stability on storage and excellent polymerizability up to $180^{\circ} \mathrm{C}^{10}$.

(1) Anionic polymerization<smiles>[R]OC/C=C1/OC(=O)C(C)OC(=O)[C@H]1C(=O)O[R]</smiles>

(2) Cationic polymerization<smiles>CC[C@H]1OC(=O)C(C)OC1=O</smiles>

(3) Coordination-insertion mechanism

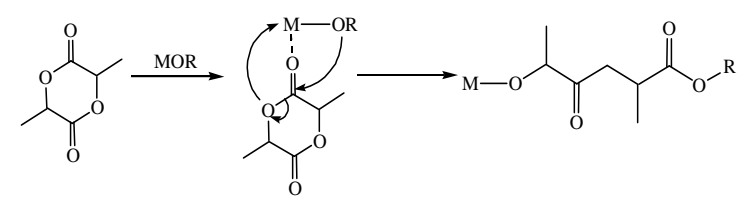

Scheme-II: Three reaction mechanisms for ring-opening polymerization of L-lactide

In this study, we examined a series of silyl-amide complexes $\left(=\mathrm{M}\left\{\mathrm{N}\left(\mathrm{SiMe}_{3}\right)_{2}\right\}_{2}\right)$ as the catalysts for the ring-opening polymerization of L-lactide. Silyl-amide complexes with several ligands have ever been used as the catalysts for ring-opening polymerization of various cyclic esters ${ }^{20,25-28}$. We chose silyl-amide complexes of zinc and calcium and compared their catalytic activities with that of tin complex to clarify the structural effects on the catalytic behaviour. Then, we tried to synthesize high-molecular-weight PLLA by melt polymerizations of L-lactide by using these biocompatible catalysts.

\section{EXPERIMENTAL}

L-Lactide (L-LA: m.p. $95^{\circ} \mathrm{C}, 99.8 \%$ ) was supplied by Musashino Chemical Laboratory, Ltd. (Tokyo) and dried in vacuum for more than $6 \mathrm{~h}$ at $45^{\circ} \mathrm{C}$ before use. $\mathrm{Zn}\left\{\mathrm{N}\left(\mathrm{SiMe}_{3}\right)_{2}\right\}_{2}$ and $\mathrm{Sn}\left\{\mathrm{N}\left(\mathrm{SiMe}_{3}\right)_{2}\right\}_{2}$ were purchased from Aldrich. A solution of $0.5 \mathrm{M} \mathrm{KN}\left(\mathrm{SiMe}_{3}\right)_{2}$ in toluene and 1-dodecanol (lauryl alcohol) were purchased from Tokyo Chemical Industry Co., Ltd (Tokyo) and Nacalai Tesque Co. (Kyoto), respectively. These materials were used as received. $\mathrm{Ca}\left\{\mathrm{N}\left(\mathrm{SiMe}_{3}\right)_{2}\right\}_{2}$ was prepared according to the literature procedure ${ }^{30}$. All manipulations were conducted under an inert atmosphere of nitrogen using the standard Schlenk-line and glovebox techniques.

Measurements: $300 \mathrm{MHz}{ }^{1} \mathrm{H}$ NMR spectra were recorded in deuterated chloroform $\left(\mathrm{CDCl}_{3}\right)$ containing 0.03 vol \% tetramethylsilane on a Bruker AV-300 NMR spectrometer and were referenced to the residual solvent resonance $\left(\mathrm{CDCl}_{3}, \delta 7.26\right)$. Gel permeation chromatography (GPC) was carried out using a Shimadzu system consisting of a LC-10A pump, a refractiveindex detector and a C-R7A plus Chromatopac data processor equipped with a set of two Tosoh TSK gel-GMH $\mathrm{HH}_{\mathrm{HR}} \mathrm{M}$ columns. The sample was eluted with dioxolane as the solvent at $45^{\circ} \mathrm{C}$ and at $0.75 \mathrm{~mL} / \mathrm{min}$ in flow rate. The molecular weights were calibrated using polystyrene standards.

Solution polymerization: L-Lactide $(0.20 \mathrm{~g}, 1.39 \mathrm{mmol})$ was dissolved in $2.5 \mathrm{~mL}$ of $\mathrm{CH}_{2} \mathrm{Cl}_{2}$ and a $\mathrm{CH}_{2} \mathrm{Cl}_{2}$ solution of lauryl alcohol (0.02 mmol) was added as the initiator. Then, a predetermined amount of a catalyst $(0.01 \mathrm{mmol})$ was added to this solution $([\mathrm{L}-\mathrm{LA}] /[\mathrm{cat}]=139: 1$.$) and the reaction mixture$ was stirred at r.t. or $50^{\circ} \mathrm{C}$. After a desired time, the polymerization was quenched by adding an excess of methanol. The polymer precipitates obtained were filtered and dried under vacuum to constant weight. The polymerization was also conducted in $\mathrm{CHCl}_{3}$ and THF for which the reaction temperature was set at $60{ }^{\circ} \mathrm{C}$ with other conditions being identical.

Kinetic studies: L-Lactide $(0.20 \mathrm{~g}, 1.39 \mathrm{mmol})$ was dissolved in $2.5 \mathrm{~mL}$ of $\mathrm{CH}_{2} \mathrm{Cl}_{2}$ and added with a solution of 1-dodecanol $(0.02 \mathrm{mmol})$ as an initiator. A catalyst $(0.01 \mathrm{mmol})$ was then added to this solution $([\mathrm{L}-\mathrm{LA}] /[$ cat. $]=139: 1)$ and the reaction mixture was stirred at $45{ }^{\circ} \mathrm{C}$. At desired time intervals, an aliquot of the solution was taken out and evaporated to dryness in a hood.

Melt polymerization: L-Lactide $(1 \mathrm{~g}, 6.95 \mathrm{mmol})$ and a certain amount of $\mathrm{CH}_{2} \mathrm{Cl}_{2}$ solution of 1-dodecanol ( $0.01 \mathrm{mmol}$ quantity) were placed in a test tube and dried in vacuum at room temperature for $1 \mathrm{~h}$. Then, a predetermined amount of $\mathrm{Zn}\left\{\mathrm{N}\left(\mathrm{SiMe}_{3}\right)_{2}\right\}_{2}\left(5.00 \times 10^{-3} \mathrm{mmol}\right)$ was added to the mixture. The resultant solid mixture was heated at $120{ }^{\circ} \mathrm{C}$ for meltpolymerization. After a desired time, the whole product was dissolved in a $\mathrm{CH}_{2} \mathrm{Cl}_{2}$ and reprecipitated into an excess of methanol. The polymer precipitates obtained were filtered and dried under vacuum to constant weight. When $\mathrm{Ca}\left\{\mathrm{N}\left(\mathrm{SiMe}_{3}\right)_{2}\right\}_{2}$ $\left(5.00 \times 10^{-3} \mathrm{mmol}\right)$ was used as the catalyst, it was added as a toluene solution and the tube was evacuated at room temperature for $3 \mathrm{~h}$ to evaporate the toluene. The other procedures were identical. 


\section{RESULTS AND DISCUSSION}

We examined solution polymerization of L-lactide with commercially available silyl-amide complexes, $\mathrm{Zn}\left\{\mathrm{N}\left(\mathrm{SiMe}_{3}\right)_{2}\right\}_{2}$ and $\mathrm{Sn}\left\{\mathrm{N}\left(\mathrm{SiMe}_{3}\right)_{2}\right\}_{2}$, as the catalysts in order to optimize the reaction conditions.

Kinetic studies: The catalytic behaviour of the silyl-amide complexes in the ring-opening polymerization of L-lactide was evaluated by kinetic studies. In addition to the $\mathrm{Zn}$ and the $\mathrm{Sn}$ silyl-amide complexes, a related Ca complex was synthesized by the reaction of $\mathrm{KN}\left(\mathrm{SiMe}_{3}\right)_{2}$ and calcium iodide and used.

Table-1 compares the molecular weights and dispersities of the obtained polymers. The PLLA synthesized with the $\mathrm{Zn}$ complex showed a $M_{n}$ near the theoretical value with narrow dispersity. The Zn complex without 1-dodecanol added also gave a PLLA with $M_{n}$ near 10,000 Da, although its molecular weight distribution was wide. It may be attributed to the slow initiation by the $\mathrm{N}\left(\mathrm{SiMe}_{3}\right)_{2}$. The PLLA obtained with the $\mathrm{Sn}$ complex in the presence of 1-dodecanol had a $\mathbf{M}_{n}$ twice the theoretical value, indicating that only one ligand in the $\mathrm{Sn}$ complex had been used for the initiation. The PLLA obtained with the Sn complex in the absence of 1-dodecanol had a $M_{n}$ higher than 40,000 Da, suggesting that the Sn catalyst involved in the insertion reaction with lactide should have higher activity for the polymerization. The difference in the initiation activity between the $\mathrm{N}\left(\mathrm{SiMe}_{3}\right)_{2}$ group and the OR group caused the big difference in the $M_{n}$ value.

\begin{tabular}{ccccc}
\multicolumn{5}{c}{ TABLE-1 } \\
\multicolumn{5}{c}{ MOLECULAR WEIGHTS OF PLLA } \\
\hline $\mathrm{M}$ & Initiator & $\mathrm{M}_{\mathrm{n}}$ (theoretical) & $\mathrm{M}_{\mathrm{n}}(\mathrm{GPC})$ & $\mathrm{Mw} / \mathrm{M}_{\mathrm{n}}$ \\
\hline $\mathrm{Zn}$ & - & 10000 & 12400 & 1.73 \\
$\mathrm{Zn}$ & $\mathrm{C}_{12} \mathrm{H}_{25} \mathrm{OH}$ & 10000 & 12900 & 1.18 \\
$\mathrm{Sn}$ & - & 10000 & 44400 & 1.33 \\
$\mathrm{Sn}$ & $\mathrm{C}_{12} \mathrm{H}_{25} \mathrm{OH}$ & 10000 & 21000 & 1.09 \\
\hline
\end{tabular}

Structures of silyl-amide complexes: Fig. 1 shows the space-filling models of the three silyl-amide complexes. Although the metal centers of the $\mathrm{Sn}$ and the $\mathrm{Zn}$ complex are buried in the bulky ligands of $\mathrm{N}\left(\mathrm{SiMe}_{3}\right)_{2}$, while the large center of the $\mathrm{Ca}$ complex is exposed. This steric space makes the coordination of L-lactide easier and causes faster rate of conversion in the early stage of the polymerization despite its small polarization. Namely, the effect of ionic radius exceeds that of the M-N bonds polarization on the catalytic behaviour. The large ionic radius results in the slow conversion in the following stage showing the enhanced association nature. After the initiating reaction, the $\mathrm{Ca}$ center becomes less sterically hindered as more lactides are inserted between the M-N bonds. It facilitates the association of the $\mathrm{Ca}$ center to block the coordination of L-lactide and to finally hinder the propagation ${ }^{27}$.

Ligand exchange reaction: In order to confirm the effect of 1-dodecanol on the ring-opening polymerization of L-lactide, we measured the ${ }^{1} \mathrm{H}$ NMR spectra of the mixtures of the silylamide complexes and 1-dodecanol.

Fig. 2 shows the spectra obtained for the respective complexes. The $\alpha$-methylene signal of the metal dodecanyl oxide is detected at the higher magnetic field for the Ca complex,

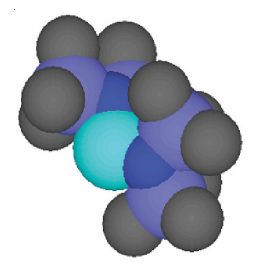

$\mathrm{Zn}$

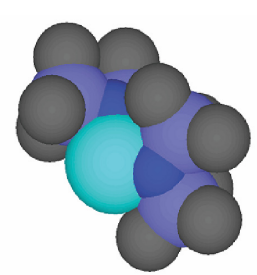

$\mathrm{Sn}$

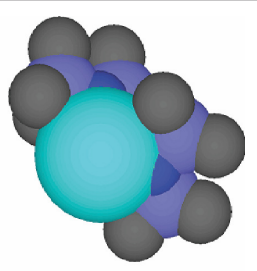

$\mathrm{Ca}$
Fig. 1. Space-filling models of the silyl-amide complexes. Hydrogen atoms are omitted for clarity

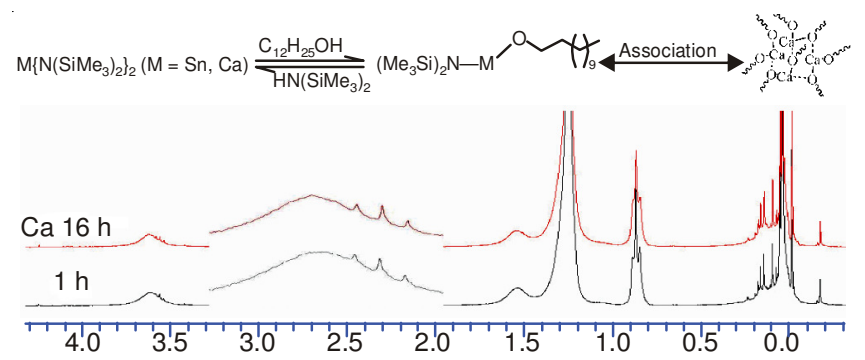

Fig. 2. Ligand exchange of the $\mathrm{N}\left(\mathrm{SiMe}_{3}\right)_{2}$ group with the OR group monitored by ${ }^{1} \mathrm{H}$ NMR

suggesting that the ligand exchange reaction proceeds rapidly, however, the signal intensity does not further increase.

The ligand exchange may therefore, correlate with the degree of the polarization of the M-N bond. In the Ca complex having lower polarization, the hydroxyl molecules are allowed to occur the ligand exchange reaction.

In the Ca complex not only the signal of $\alpha$-methylene shown at lower magnetic field, but also other signals are broadened. This signal broadening is attributed to the association/ dissociation equilibrium of the Ca center competing with the NMR time scale. After generating the monomeric alkoxide, it may associate into a dimer or other higher oligomers by the aide of free hydroxyl and silyl-amide ligands. This association causes the decreased catalytic activity in the lactide polymerization.

To prevent this association of the Ca center, we performed the ring-opening polymerization of L-lactide in THF which is a coordinating solvent. Fig. 3 shows the plots of conversion as compared with the plots performed in $\mathrm{CH}_{2} \mathrm{Cl}_{2}$. The conversion increased in THF even after the initial fast conversion had stopped. So the association of the Ca metal center may have partly been hindered by the coordination of THF in spite of the slow polymer conversion due to the competitive unfavorable coordination of THF and L-lactide.

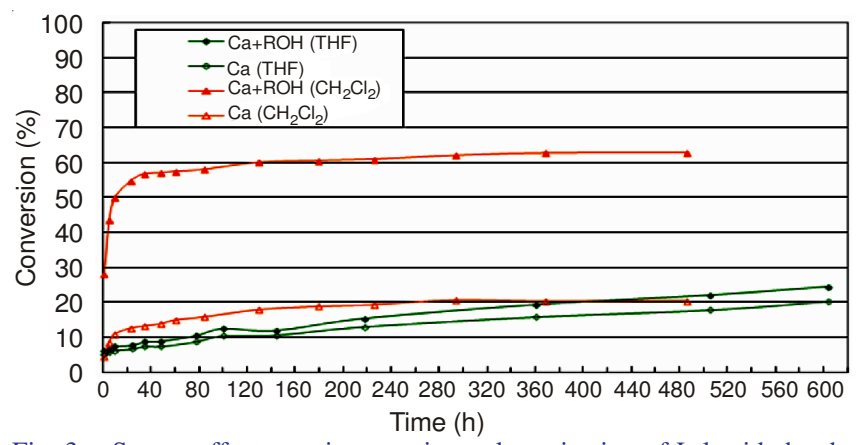

Fig. 3. Sovent effects on ring-opening polymerization of L-lactide by the catalysis of $\mathrm{Ca}\left(\mathrm{N}\left(\mathrm{SiMe}_{3}\right)_{2}\right)_{2}$ 
Mechanistic study: From the above results, the mechanism of ring-opening polymerization of lactide with each silyl-amide complex can be postulated as shown in Schemes-III.

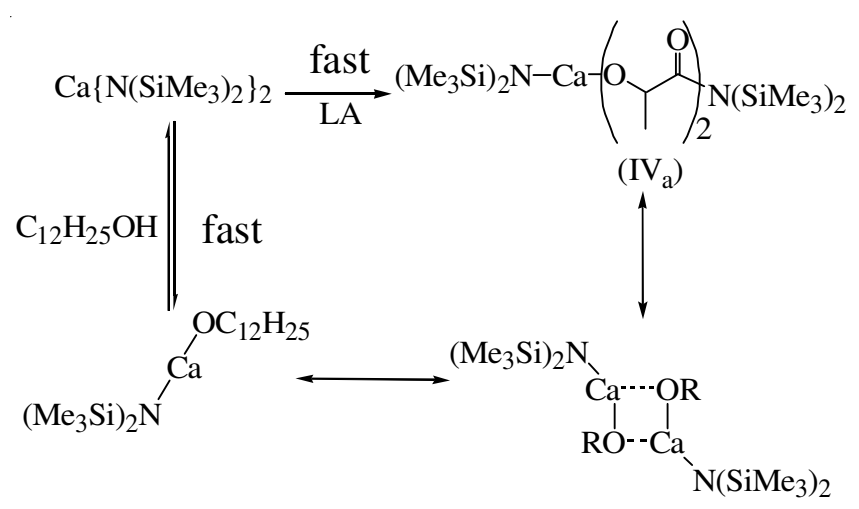

$\left(\mathrm{IV}_{\mathrm{b}}\right)$

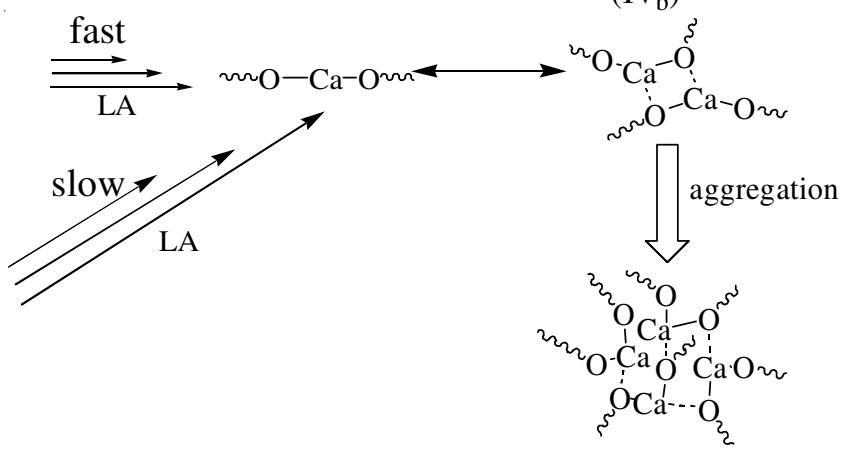

Scheme-III: Plausible mechanisms of ring-opening polymerization of Llactide with $\mathrm{Ca}\left\{\mathrm{N}\left(\mathrm{SiMe}_{3}\right)_{2}\right\}_{2} . \mathrm{R}=\mathrm{OC}_{12} \mathrm{H}_{25}, \mathrm{CH}\left(\mathrm{CH}_{3}\right) \mathrm{COOCH}$ $\left(\mathrm{CH}_{3}\right) \mathrm{COON}\left(\mathrm{SiMe}_{3}\right)_{2}$

The ring-opening polymerization mechanism with the $\mathrm{Sn}$ complex is simpler due to its facile ligand exchange of the $\mathrm{N}\left(\mathrm{SiMe}_{3}\right)_{2}$ group with 1-dodecanol. In the presence of 1 -dodecanol, the half-alkoxyl species is quickly formed. The initiation is induced by this alkoxyl ligand and followed by the propagation. The easy insertion of lactide monomer to alkoxyl/Sn bond may be due to the less sterically hindered lone pair of the alkoxyl group. So, the obtained polymer had a $\mathbf{M}_{n}$ twice the theoretical value (Table-1). In the absence of 1 -dodecanol, very slow initiation is induced by the amide route because of the lower polarizability of the silyl-amide/Sn bond. But once initiated, fast propagation is induced to give a highmolecular-weight polymer.

The similar rapid dimerization/dissociation equilibrium also occurs with the Ca complex (Scheme-III). Due to its bigger ionic radius, the $\mathrm{Ca}$ center is exposed even after the insertion of several lactide to favour the formation of the dimer. This metal association is preferred to the coordination of lactide monomer and finally induces association to hinder the propagation.

These mechanistic analyses reveal the superior reactivity which only one well-defined catalytic species can work. It enables the polymerization to give well-controlled polymer having narrow molecular distribution. With the Ca catalyst, the ionic association hinders the propagation of lactide and prevention of the association is essential for its real application as the ring-opening polymerization catalyst.

Melt polymerization of L-lactide with silyl-amide complexes: Melt polymerization of L-lactide was examined with the Ca complex to obtain high-molecular-weight PLLA. Table-2 summarizes the results. The [monomer]/[catalyst] ratio was set at 1390 with which the theoretical molecular weight of the obtained polymer ought to be 100,000 Da.

For the Ca complex, the conversions recorded in the presence and absence of 1-dodecanol were not so different with other reaction conditions being identical. This result is somewhat different from that of the solution polymerization. The initiation activity of $\mathrm{N}\left(\mathrm{SiMe}_{3}\right)_{2}$ should be highly enhanced at the high temperature of the present melt polymerization.

The polymerization catalyzed by the Ca complex showed a slow polymerization rate. It needed over $120 \mathrm{~h}$ to reach $70 \%$ in conversion. The polymer yields after the reprecipitation were very low relative to the conversion. Particularly, in the presence of 1-dodecanol, the yield was only $18 \%$. It suggests that the chain-scrambling has been accelerated by 1 -dodecanol to hinder the molecular weight increase. This frequent chainscrambling may be correlated with the rapid dimerization/ dissociation equilibrium of the Ca catalyst mentioned above. Since the Mn and the dispersity were similar in the presence and absence of 1-dodecanol, the dimerization is thought to become the dominant reaction after the insertion of several lactide monomers. Due to the association nature of the $\mathrm{Ca}$ center, the polymer chain cannot propagate after reaching a certain length.

\section{Conclusion}

In this study, we revealed the characters of the silyl-amide complexes by which the catalytic activity on the ring-opening polymerization of L-lactide was affected. The initiation activities of the two ligands caused the wider molecular weight distribution of the resultant polymers. Although bigger ionic radius of the metal center induced the higher catalytic activity, it facilitated the association of the metal centers to block the coordination of L-lactide and to hinder the propagation. The facile generation of monomeric alkoxide species was found out to be important to control the ring-opening polymerization. Therefore, with the Ca complexes, the generation of monomeric

\begin{tabular}{|c|c|c|c|c|c|c|}
\hline & ESULT & T POLYMER & $\begin{array}{l}\text { TABLE-2 } \\
\text { N OF L-LAC }\end{array}$ & ATALYZEI & $\left.\mathrm{N}\left(\mathrm{SiMe}_{3}\right)_{2}\right)_{2}$ & \\
\hline $\mathrm{M}$ & Time & Initiator & Conversion & Yield (\%) & $\mathrm{M}_{\mathrm{n}} \times 10^{-4}$ & $\mathrm{M}_{\mathrm{w}} / \mathrm{M}_{\mathrm{n}}$ \\
\hline \multirow{4}{*}{$\mathrm{Ca}$} & $12 \mathrm{~h}$ & 1-Dodecanol & 8.63 & - & - & - \\
\hline & $12 \mathrm{~h}$ & - & 8.28 & - & - & - \\
\hline & $120 \mathrm{~h}$ & 1-Dodecanol & 68.5 & 18.4 & 1.17 & 1.22 \\
\hline & $120 \mathrm{~h}$ & - & 65.9 & 29.7 & 1.17 & 1.21 \\
\hline
\end{tabular}

Reacion temp. $=120^{\circ} \mathrm{C},[\mathrm{LA}] 0 /[\text { cat. }]_{0}=1390$ (theoretical $\left.\mathrm{M}_{\mathrm{n}}=100,000\right),[1 \text {-dodecanol }]_{0} \times 2,[\mathrm{~L}-\mathrm{Lactide}]_{0}$ : the initial monomer concentration of $\mathrm{L}-$ lactide, [cat.] $]_{0}$ : the initial concentration of $\mathrm{Ca}\left\{\mathrm{N}\left(\mathrm{SiMe}_{3}\right)_{2}\right\}_{2}$. 
species must be required in order to obtain well-controlled polymer having narrow molecular distribution. The Ca complex showed slow polymerization to give only low-molecularweight polymers due to its rapid dimerization and the association equilibrium. Further studies will be needed to create active biocompatible catalysts that can be utilized for the lactide polymerization.

\section{ACKNOWLEDGEMENTS}

This work was supported by the Human Resources Development program (No. 20114010203130) of the Korea Institute of Energy Technology Evaluation and Planning (KETEP) grant funded by the Korea Government Ministry of Trade, Industry and Energy and the program for Climate Change Specialists of the Ministry of Environment in Korea Government for helpful supports on this study.

\section{REFERENCES}

1. E. Lillie and R.C. Schulz, Makromol. Chem., 176, 1901 (1975).

2. F.E. Kohn, J.W.A. Van Den Berg, G. Van De Ridder and J. Feijen, $J$. Appl. Polym. Sci., 29, 4265 (1984).

3. J.W. Leenslag and A.J. Pennings, Polymer, 28, 1695 (1987).

4. H.R. Kricheldorf and M. Sumbel, Eur. Polym. J., 25, 585 (1989).

5. M. Ajioka, E. Enomoto, K. Suzuki and A. Yamaguchi, Bull. Chem. Soc. Jpn., 68, 2125 (1995).

6. S.-I. Moon, C.-W. Lee, M. Miyamoto and Y. Kimura, J. Polym. Sci. A Polym. Chem., 38, 1673 (2000).

7. S.-I. Moon, C.-W. Lee, I. Taniguchi, M. Miyamoto and Y. Kimura, Polymer, 42, 5059 (2001).

8. S.-I. Moon, I. Taniguchi, M. Miyamoto, Y. Kimura and C.-W. Lee, High Perform. Polym., 13, 317 (2001).

9. S.-I. Moon and Y. Kimura, Polym. Int., 52, 299 (2003).
10. A.P. Gupta and V. Kumar, Eur. Polym. J., 43, 4053 (2007).

11. D. Pospiech, H. Komber, D. Jehnichen, L. Haussler, K. Eckstein, H. Scheibner, A. Janke, H.R. Kricheldorf and O. Petermann, Biomacromolecules, 6, 439 (2005).

12. H.R. Kricheldorf and A. Stricker, Macromol. Chem. Phys., 200, 1726 (1999).

13. E. Ruckenstein and Y. Yuan, J. Appl. Polym. Sci., 69, 1429 (1998).

14. J.-H. Kim and J.H. Lee, Polym. J., 34, 203 (2002).

15. J. Cai, K.J. Zhu and S.L. Yang, Polymer, 39, 4409 (1998).

16. M.H. Chisholm, J.C. Gallucci and C. Krempner, Polyhedron, 26, 4436 (2007).

17. Z. Zhong, P.J. Dijkstra and J. Feijen, J. Am. Chem. Soc., 125, 11291 (2003).

18. P.A. Cameron, D. Jhurry, V.C. Gibson, A.J.P. White, D.J. Williams and S. Williams, Macromol. Rapid Commun., 20, 616 (1999).

19. Z. Zhong, S. Schneiderbauer, P.J. Dijkstra, M. Westerhausen and J. Feijen, Polym. Bull., 51, 175 (2003).

20. M.H. Chisholm, J.C. Gallucci and K. Phomphrai, Inorg. Chem., 44, 8004 (2005).

21. M.H. Chisholm, J.C. Gallucci, H. Zhen and J.C. Huffman, Inorg. Chem., 40, 5051 (2001).

22. D.J. Darensbourg, W. Choi and C.P. Richers, Macromolecules, 40, 3521 (2007).

23. H. Chen, H. Tang and C. Lin, Polymer, 48, 2257 (2007).

24. M.H. Chisholm, J.C. Gallucci and G. Yaman, Inorg. Chem., 46, 8676 (2007).

25. M.H. Chisholm, J.C. Gallucci and K. Phomphrai, Inorg. Chem., 43, 6717 (2004).

26. D.J. Darensbourg, W. Choi, O. Karroonnirun and N. Bhuvanesh, Macromolecules, 41, 3493 (2008).

27. H. Ma and J. Okuda, Macromolecules, 38, 2665 (2005).

28. A. Amgoune, C.M. Thomas, T. Roisnel and J.-F. Carpentier, Chem. Eur. J., 12, 169 (2006).

29. C.W. Lee, S. Kuno and Y. Kimura, Macromolecular Res., 21, 385 (2013).

30. E.D. Brady, T.P. Hanusa, M. Pink and V.G. Young, Inorg. Chem., 39, 6028 (2000). 